\title{
The Influence of Bauschinger Effect in Straightening Process
}

\author{
Hai-Lian Gui, ${ }^{1,2}$ Qiang Li, ${ }^{3}$ and Qing-Xue Huang ${ }^{1,2}$ \\ ${ }^{1}$ Heavy Industry Engineering Center of China Ministry of Education, Taiyuan 030024, China \\ ${ }^{2}$ Material Science \& Engineering Science College, Taiyuan University of Science and Technology, Taiyuan 030024, China \\ ${ }^{3}$ Technology Center, Taiyuan Heavy Industry Co., Ltd., Taiyuan 030024, China \\ Correspondence should be addressed to Hai-Lian Gui; guihailian@qq.com
}

Received 22 October 2014; Revised 6 January 2015; Accepted 6 January 2015

Academic Editor: Yannis Dimakopoulos

Copyright (C) 2015 Hai-Lian Gui et al. This is an open access article distributed under the Creative Commons Attribution License, which permits unrestricted use, distribution, and reproduction in any medium, provided the original work is properly cited.

\begin{abstract}
The yield stress changes during the straightening process, because of the Bauschinger effect. This effect leads to a different reduction rate in each straightening roller. To accurately estimate the straightening effect of the rolled piece, the Bauschinger effect must be considered in calculating the reduction rate. In this paper, the straightening model is described by the fast multipole boundary element method. The Bauschinger effect model is discussed in the elastic loading region and elastic plastic loading region. Young's modulus reduction and the reverse yield stress reduction are obtained for the straightening force model. The straightening force formula including the Bauschinger effect is determined by analyzing the tension and compression processes. This formula reflects the changes of the yield stress and the straightening force in the tension and compression processes. It is concluded that the Bauschinger effect is a very important factor for the precise estimation of the straightening force.
\end{abstract}

\section{Introduction}

The Bauschinger [1] effect was proposed by Bauschinger in 1881. He noted that after plastic deformation the elastic limit of a metal was lower for subsequent loading in the reverse direction than for loading in the same direction. In recent years, this phenomenon has been a subject of numerous studies that showed that this effect is more general and complex than it had been thought originally. Much of this study has been summarized in recent review papers. Liu et al. [2] have experimentally studied the Bauschinger effect in sheet metal. A device to avoid the bending of the specimen in compression progress was designed and the rounding of the reverse flow curve was obtained, yielding at low reverse stresses. Ghorbanpour et al. [3] studied an independent kinematic hardening material model with the reverse yielding point defined by the Bauschinger effect factor (BEF).

The Bauschinger phenomenon can cause reverse yielding to occur at the surface of the straightening pieces. Reverse yielding caused by highly compressive residual stresses can affect the performance characteristics and product quality. Therefore, the Bauschinger effect is a very important factor in the straightening process. Many studies have discussed the influence of various factors, such as the roller distance, roll gap of up roll and down roll, straightening, and the metal material, on the straightening force in the framework of the traditional straightening theory. Zhou et al. [4] obtained the reverse bend curvature and work hardening modulus using the ANSYS/LS-DYNA analysis. Sun and Chen [5] analyzed the frame of prestress straightening machine based on the ANSYS Workbench. Li et al. [6] optimized the parameter by simulation of the straightening process using ANSYS/LSDYNA. The relationship between the straightening force and the relative strain on the column neutral layer is obtained by using the polynomial fit. However, in the traditional straightening analysis, the Bauschinger effect had been ignored. This may lead to a systematic error for the work curve in straightening process that can reach up to $40 \%$.

Unlike the traditional methods, the straightening model used in this work is described by the fast multipole boundary element method (FM-BEM). The Bauschinger effect is considered in this model and the work curve for the straightening process is obtained using the analysis of the FM-BEM results. The stress of the cross section in the loading process and unloading process is then discussed. It is concluded that the Bauschinger effect is important for the precise determination 
of the deformation resistance and improving straightening effect.

\section{The Straightening Model Based on FM-BEM}

The straightening process is considered as an inverse problem of the plate bending. Using the fundamental solution of plate bending, the boundary integral equation of the straightening process can be written as [7]

$$
\begin{gathered}
b \int_{\Omega} w^{*} d \Omega=C w_{i}+\int_{\Gamma}\left(m_{n}^{*} \beta_{n}+t^{*} w\right) d \Gamma+\sum_{k=1}^{L} t_{k}^{c *} w_{k} \\
-\int_{\Gamma}\left(m_{n} \beta_{n}^{*}+t w^{*}\right) d \Gamma-\sum_{k=1}^{L} t_{k}^{c} w_{k}^{*}, \\
C= \begin{cases}1, & \text { interior point, } \\
\frac{1}{2}, & \text { smooth boundary, } \\
t & =q+\frac{\partial m_{s}}{\partial s}=q-\beta_{s}, \\
\sum_{k=1}^{L} t_{k}^{c *} w_{k} & =\int_{\Gamma}\left(\frac{\partial m_{s}^{*}}{\partial s} w+m_{s}^{*} \frac{\partial w}{\partial s}\right) d \Gamma, \\
\sum_{k=1}^{L} t_{k}^{c} w_{k}^{*} & =\int_{\Gamma}\left(\frac{\partial m_{s}}{\partial s} w^{*}+m_{s} \frac{\partial w^{*}}{\partial s}\right) d \Gamma,\end{cases}
\end{gathered}
$$

where $b$ denotes the vertical force; $C$ is the boundary coefficient; $\beta_{n}$ and $\beta_{s}$ denote the normal angle and the tangential angle at an arbitrary point on the boundary, respectively; $\beta_{n}^{*}$ and $\beta_{s}^{*}$ are the known values of $\beta_{n}$ and $\beta_{s} ; m_{n}$ and $m_{s}$ denote the bending moment and the torsional moment in a cross section of the plate, respectively; $m_{n}^{*}$ and $m_{s}^{*}$ are the known values of $m_{n}$ and $m_{s} ; q$ is the shear force; and $q^{*}$ is the known value of $q$.

$w^{*}$ is the fundamental solution of the plate bending problem and can be written as

$$
w^{*}=\frac{r^{2}}{8 \pi D} \ln r=\frac{r^{2}}{8 \pi D}\left(\ln y_{i}-\sum_{k=1}^{\infty} f(x)_{k} g_{k}\left(y_{i}\right)\right),
$$

where $f(x)_{k}=x^{k} / k, g_{k}\left(y_{i}\right)=1 / y_{i}^{k}$, and $D=E h / 12\left(1-v^{2}\right)$ is the bending rigidity.

\section{Bauschinger Effect Model}

First, the initial stress and strain relationship are given in Cartesian coordinates for the loading process and the unloading process.

(1) Loading process is as follows:

in elastic state

$$
\sigma=E_{1} \varepsilon, \quad \varepsilon \leq \varepsilon_{s} ;
$$

in strain hardening state

$$
\sigma=A_{1}+A_{2} \varepsilon, \quad \varepsilon \geq \varepsilon_{s} .
$$

(2) Unloading process is as follows:

in elastic state

$$
\sigma^{*}=E_{2} \varepsilon^{*}, \quad \varepsilon^{*} \leq \varepsilon_{s}^{*}
$$

in strain hardening state

$$
\sigma=A_{3}+A_{4} \varepsilon^{*}, \quad \varepsilon^{*} \geq \varepsilon_{s}^{*},
$$

where $\sigma$ and $\sigma^{*}$, respectively, denote the stress in the loading process and the unloading process, $\varepsilon$ and $\varepsilon^{*}$ denote the strain in the loading process and the unloading process, $E_{1}$ and $E_{2}$ denote the elastic modulus in the loading process and the unloading process, $A_{1}, A_{2}, A_{3}, A_{4}$ denote the strain hardening coefficients, and $\varepsilon_{s}$ and $\varepsilon_{s}^{*}$ denote loading the yield strain in the loading process and the unloading process.

In the straightening process, the straightening piece deformation is considered as a plane strain problem. It follows the Von Mises yield law: $\sigma_{\text {eq }}=\sigma_{s}$, where $\sigma_{\text {eq }}$ is an equivalent stress and $\sigma_{s}$ is the yield limit:

$$
\begin{aligned}
& \sigma_{\mathrm{eq}}=\sqrt{\frac{1}{2}\left[\left(\sigma_{x}-\sigma_{y}\right)^{2}+\left(\sigma_{y}-\sigma_{z}\right)^{2}+\left(\sigma_{z}-\sigma_{x}\right)^{2}\right]}, \\
& \varepsilon_{\mathrm{eq}}=\sqrt{\left(\varepsilon_{x}-\varepsilon_{y}\right)^{2}+\left(\varepsilon_{y}-\varepsilon_{z}\right)^{2}+\left(\varepsilon_{z}-\varepsilon_{x}\right)^{2}} .
\end{aligned}
$$

When $e>0$, the neutral layer is offset downward, while, for $e<0$, the neutral layer is offset upward and $e=0$ means that the neutral layer has a zero offset; namely, the geometric central layer and the stress neutral layer coincide. The stress distribution of the rolled piece cross section is shown in Figure 1 , where $2 h$ is the rolled piece thickness, $2 b$ is the roller distance, and $y_{s}$ and $y_{s^{\prime}}$ are, respectively, the thickness of the elastic deformation in the tensile zone and in the compression region.

In the loading process, the cross section can be divided into an elastic loading region $\left(-y_{s^{\prime}} \leq y \leq 0\right)$ and an elastic plastic loading region $\left(-h \leq y \leq-y_{s^{\prime}}\right)$. When the equivalent stress is not equal to the yield stress limit, only the elastic region exists. As the loads increase, the stresses move into the elastic plastic loading region.

Through an analysis of the cross section (Figure 2), the basic control equation for loading is

$$
d \sigma_{y}=\left(\sigma_{y}-\sigma_{x}\right) d \rho=\frac{2}{\sqrt{3}} \sigma_{\text {eq }} \frac{d \rho}{\rho} .
$$

(1) In the elastic loading region

$$
\sigma_{y}=\frac{2 E_{1}}{3 r_{c}}\left(y+2 y_{s^{\prime}}\right) y+\frac{2}{\sqrt{3}} \sigma_{s^{\prime}} y .
$$

(2) In the elastic plastic loading region

$$
\begin{aligned}
\sigma_{y}= & \frac{2}{\sqrt{3}} \sigma_{s^{\prime}}(y+h) \\
& +\frac{2}{3} \frac{A_{2}}{r_{c}}\left[\left(y+2 y_{s^{\prime}}\right) y+h\left(2 y_{s^{\prime}}-h\right)\right]+\bar{P} .
\end{aligned}
$$




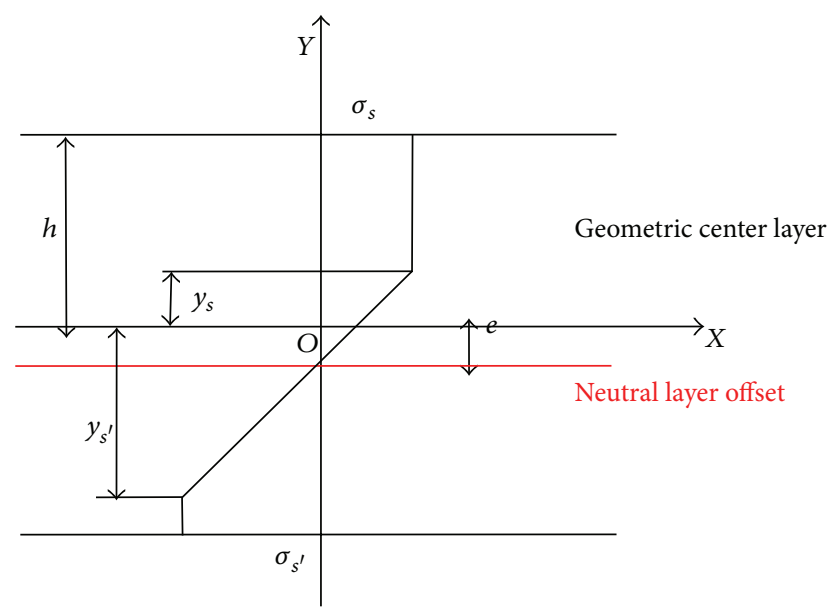

FIGURE 1: Stress distribution of the rolled piece cross section.

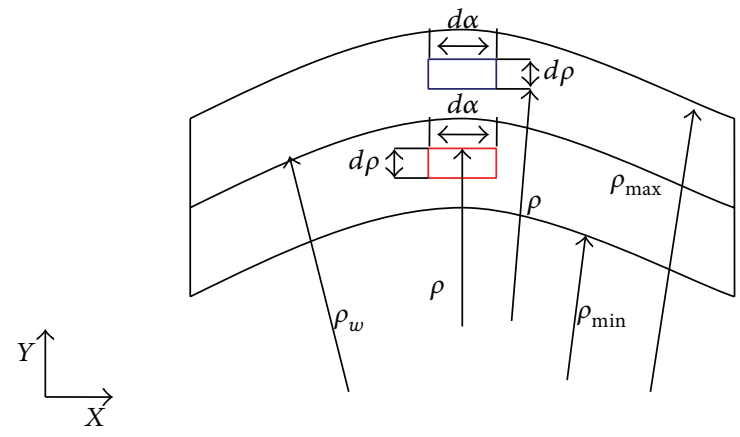

FIGURE 2: The state of the plate after bending.

When $y=-y_{s^{\prime}}$, the stress in the elastic loading region is equal to the stress in the elastic plastic loading region, so that the formula of the straightening force is obtained as follows:

$$
\bar{P}=\frac{2}{3} \frac{A_{2}}{r_{c}}\left(h-y_{s^{\prime}}\right)^{2}-\frac{2}{\sqrt{3}} \sigma_{s^{\prime}} h-\frac{2 E_{1}}{3 r_{c}} y_{s^{\prime}}^{2} .
$$

Using the same method, the unloading process can be described.

(1) In the elastic loading region

$$
\sigma_{y}^{*}=\frac{2 E_{1}}{3 r_{c}}\left(y+2 y_{s^{\prime}}\right) y+\frac{2}{\sqrt{3}} \sigma_{d}^{*} y .
$$

(2) In the elastic plastic loading region

$\sigma_{y}^{*}=\frac{2 E_{1}}{3 r_{c}}\left[\left(y+2 y_{s^{\prime}}\right) y-h\left(h-2 y_{s^{\prime}}\right)\right]+\frac{2}{\sqrt{3}} \sigma_{d}^{*}(y+h)+\bar{P}$.

\section{Straightening Process including the Bauschinger Effect}

11 rollers' straightening mechanic is discussed such as in Figure 3. The basic model parameters are shown in Tables 1-3.

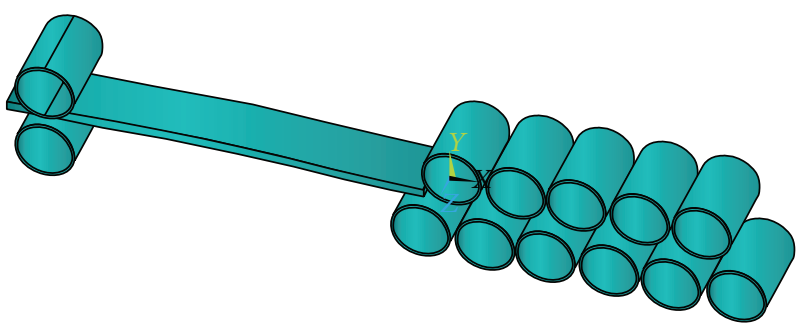

FIGURE 3: Straightening process of FEM.

TABLE 1: Process performance of roller.

\begin{tabular}{lc}
\hline Roller diameter/mm & 285 \\
Length of barrel/mm & 4200 \\
Roller spacing/mm & 300 \\
Straightening speed/mm/s & 1000 \\
\hline
\end{tabular}

TABLE 2: Materials properties of roller.

Elastic modulus/MPa

Yield limit/MPa 400

TABLE 3: Basic parameters of straightening piece.

\section{Plate length/m}

Plate thickness $/ \mathrm{m}$

Plate width $/ \mathrm{m}$

Elastic modulus/MPa

We use the Solid 164 package with $500 \times 40 \times 10$ elements. Export compression bending is $0 \mathrm{~mm}$ and the compression bending is $-2.08 \mathrm{~mm}$. The straightening process is shown in Figure 4.

Two elements are taken from the upper surface and lower surface of straightening piece, such as in Figure 5. Figure 6 shows the change of the Von Mises stress. We can conclude that the yield stress is changing after every straightening roller. Because there is a repeated tension-compression in the upper surface and lower surface, the Bauschinger effect leads to the yield stress change.

The results of the FEM analysis can be used to establish the Bauschinger effect formula. In the tension and compression experiments, the Bauschinger effect leads to the change of Young's modulus and the reverse yield stress, defined by

Young's modulus reduction: $\mathrm{BMR}=E(\varepsilon) / E=f_{1}(\varepsilon)$, reverse yield stress reduction: $\mathrm{BSR}=\sigma_{D}(\varepsilon) / \sigma_{s^{\prime}}=$ $f_{2}(\varepsilon)$. 


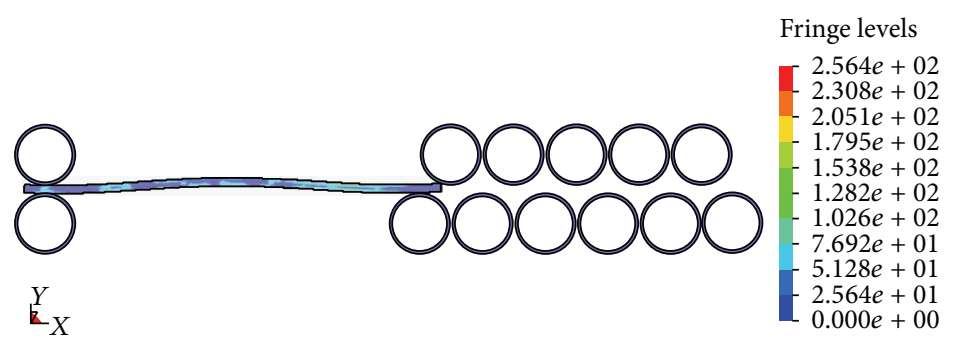

(a)

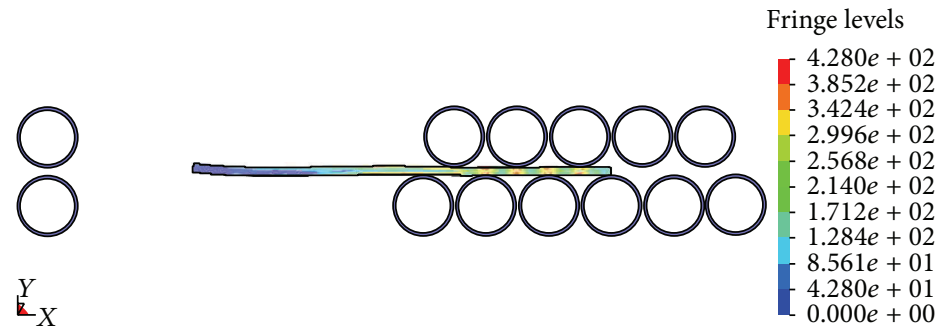

(b)

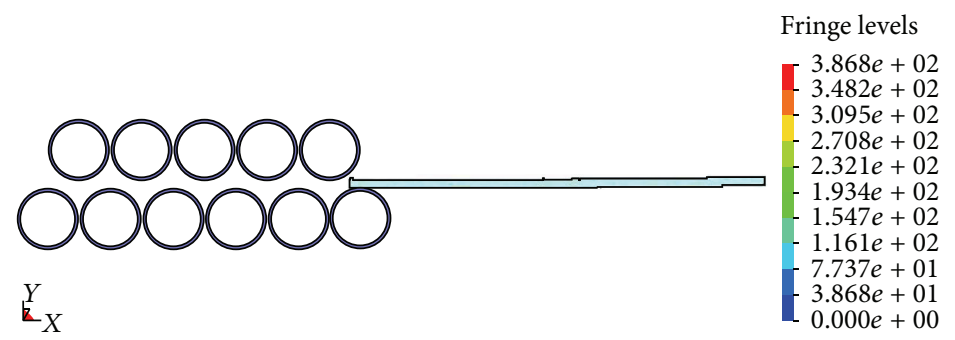

(c)

FIGURE 4: The straightening process.

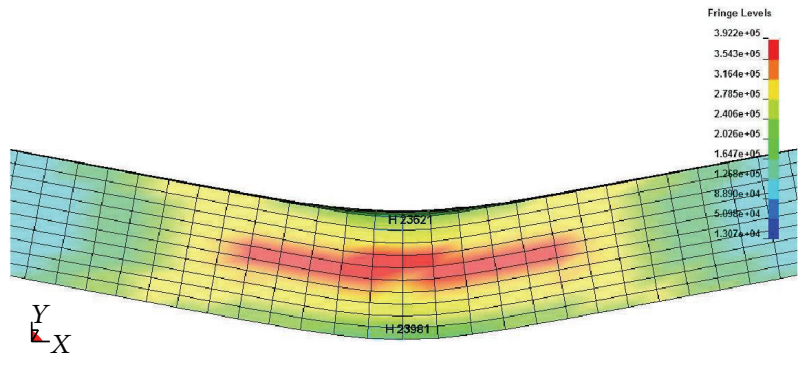

FIGURE 5: Taking two elements.

For the $n$-rollers straightening machine, the initial strain is given by

$$
\begin{gathered}
\varepsilon_{0}=\varepsilon_{\mathrm{eq}}-\varepsilon_{s}=\frac{2}{\sqrt{3}} \frac{y+y_{s^{\prime}}}{r_{c}}+\varepsilon_{s}-\varepsilon_{s}=\frac{2}{\sqrt{3}} \frac{y+y_{s^{\prime}}}{r_{c}}, \\
\operatorname{BSR}\left(\varepsilon_{0}\right)=\frac{\sigma_{D}\left(\varepsilon_{0}\right)}{\sigma_{s^{\prime}}}=f_{2}\left(\varepsilon_{0}\right),
\end{gathered}
$$

where $\varepsilon_{\mathrm{eq}}$ denotes the equivalent strain, $y_{s^{\prime}}$ denotes the elastic deformation thickness, $r_{c}$ denotes the original radius, and $\sigma_{D}$ denotes the reverse yield stress.

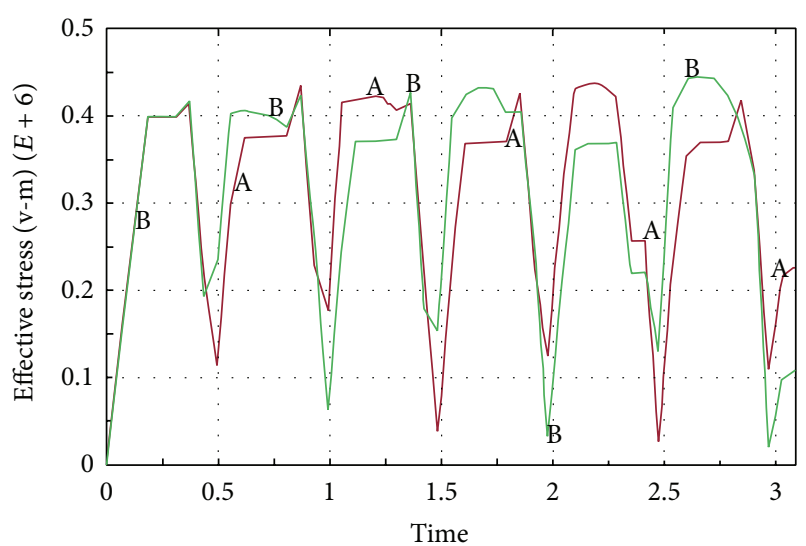

Element number

- A: 23621

B: 23981

FIgUre 6: The change of Von Mises stress.

When the straightening state in the $i$ th roll is the same as the initial state at that point, $f_{1}(\varepsilon)$ and $f_{2}(\varepsilon)$ are positive values. 
The reverse yield stress can be written as follows. In the elastic region

$\sigma_{D}\left(-y_{s^{\prime}}\right)=\operatorname{BMR}\left(-y_{s^{\prime}}\right) E_{1} \varepsilon=f_{1}\left(\varepsilon_{s}\right) E_{1} \varepsilon=f_{1}\left(\varepsilon_{s}\right) E_{1} \frac{y}{r_{c}}$.

In the elastic plastic region

$$
\begin{aligned}
\sigma_{D}\left(-y_{s^{\prime}}\right) & =\operatorname{BSR}\left(-y_{s^{\prime}}\right) \sigma_{s^{\prime}}+A_{1}+A_{2} \varepsilon \\
& =f_{2}\left(\varepsilon_{s}\right) \sigma_{s^{\prime}}+A_{1}+A_{2} \frac{y}{r_{c}}
\end{aligned}
$$

Considering the straightening force with the Bauschinger effect, the iterative formula is as follows.

Initial straightening force is as follows:

$$
\bar{F}_{0}=\bar{P}_{0}=\frac{2}{3} \frac{A_{2}}{r_{0 c}}\left(h-y_{0 s}\right)^{2}-\frac{2}{\sqrt{3}} \sigma_{s^{\prime}} h-\frac{2 E_{1}}{3 r_{0 c}} y_{0 s}^{2} .
$$

Straightening force in the elastic region is as follows:

$$
\begin{aligned}
\bar{F}_{i}= & \frac{2 A_{2}}{3}\left(\frac{\left(h+y_{i s}\right)^{2}}{r_{i c}}-\frac{\left(h+y_{(i-1) s}\right)^{2}}{r_{(i-1) c}}\right) \\
& -\frac{2 E_{1}}{3}\left(\frac{y_{i s}^{2}}{r_{i c}}+\frac{\left(h+y_{(i-1) s}\right)^{2}}{r_{(i-1) c}}\right)-\frac{2}{\sqrt{3}} f_{1}\left(\varepsilon_{s}\right) E_{1} \frac{y}{r_{(i-1) c}} h .
\end{aligned}
$$
follows:

Straightening force in the elastic plastic region is as

$$
\begin{aligned}
\bar{F}_{i}= & \frac{2 A_{2}}{3}\left(\frac{\left(h+y_{i s}\right)^{2}}{r_{i c}}-\frac{\left(h+y_{(i-1) s}\right)^{2}}{r_{(i-1) c}}\right) \\
& -\frac{2 E_{1}}{3}\left(\frac{y_{i s}^{2}}{r_{i c}}+\frac{\left(h+y_{(i-1) s}\right)^{2}}{r_{(i-1) c}}\right) \\
& -\frac{2}{\sqrt{3}}\left[f_{2}\left(\varepsilon_{s}\right) \sigma_{s^{\prime}}+A_{1}+A_{2} \frac{y}{r_{(i-1) c}}\right] h,
\end{aligned}
$$

where denotes the elastic thickness of the compressive region in the $i$ th roll. When the compressive region is lower than the central layer in the $i$ th roll, $\bar{F}_{i} \leq 0$; when the compressive region is higher than the central layer in the $(i+1)$ th roll, $\bar{F}_{i+1} \geq 0$; so $\bar{F}_{i+1} \geq 0 \geq \bar{F}_{i}$. The above formula shows that $\bar{F}_{i+1} \geq \bar{F}_{i}$ when the compressive region is lower than the central layer in the $i$ th roll and higher than the central layer in the $(i+1)$ th roll. Conversely, $\bar{F}_{i} \geq \bar{F}_{i+1}$ is obtained for the opposite case.

\section{Conclusions}

(1) The straightening model is described by FM-BEM. This model is more precise for calculation of straightening force than FEM.
(2) The Bauschinger effect on the straightening force is studied using force analysis in the loading process and the unloading process. The Bauschinger effect model is given. The Bauschinger effect is discussed for the straightening force in the elastic loading region and the elastic plastic loading region in the cross section.

(3) The formula for straightening force is given considering the Bauschinger effect. The results show that the Bauschinger effect has a significant impact on the straightening effect and cannot be neglected in a precise determination of the straightening force.

\section{Conflict of Interests}

The authors declare that there is no conflict of interests regarding the publication of this paper.

\section{Acknowledgments}

Financial supports for the project from the Outstanding Innovative Teams of Higher Learning Institutions of Shanxi (OIT, 20131086), the National Natural Science Foundation of China (51104104), 973 Project (2012CB722801), the Basic Research Project in Shanxi Province (2012021019-3), and Specialized Research Fund for the Doctoral Program of Higher Education (20111415110001) are gratefully acknowledged.

\section{References}

[1] J. Bauschinger, "Ueber die Veranderung der Elasticitatagrenze und dea Elasticitatamoduls verschiadener Metalle," Zivilingenieur, vol. 27, pp. 289-348, 1881.

[2] D. Liu, J. Zhuang, and G. Li, "Research on bauschinger effect of sheet metal by experiments," China Mechanical Engineering, vol. 24, no. 4, pp. 542-556, 2013.

[3] A. Ghorbanpour, A. Loghman, H. Khademizadeh, and M. Moradi, "The overstrain of thick-walled cylinders considering the Bauschinger effect factor (BEF)," KSME International Journal, vol. 17, no. 4, pp. 477-483, 2003.

[4] C.-L. Zhou, G.-D. Wang, X.-H. Liu, and J.-P. Qin, "Work hardening modulus and reverse bend curvature in plate hot roller leveling," Journal of Plasticity Engineering, vol. 14, no. 4, pp. 133-135, 2007.

[5] Z. Sun and W. Chen, "Research on straightening force measuring technology for pre-stress straightening machine," Applied Mechanics and Materials, vol. 239-240, pp. 680-684, 2013.

[6] S. Li, Y. Wang, and L. Xu, "The numerical simulation and parameter optimization analysis of straightening machine straightening process based on ANSYS/LS-DYNA," Advanced Materials Research, vol. 630, pp. 133-135, 2013.

[7] H.-L. Gui, Q. Li, Q.-X. Huang, and G.-X. Shen, "Analysis of contact problem using improved fast multipole bem with variable elements length theory," Journal of Marine Science and Technology, vol. 21, no. 1, pp. 1-7, 2013. 


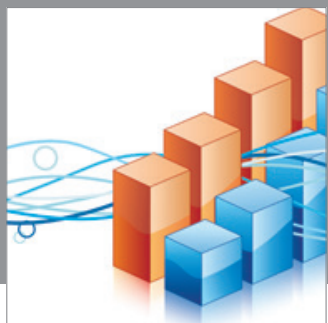

Advances in

Operations Research

mansans

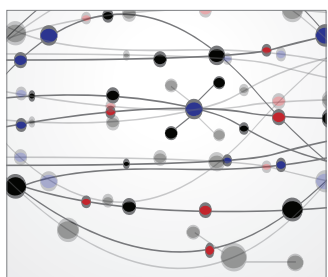

The Scientific World Journal
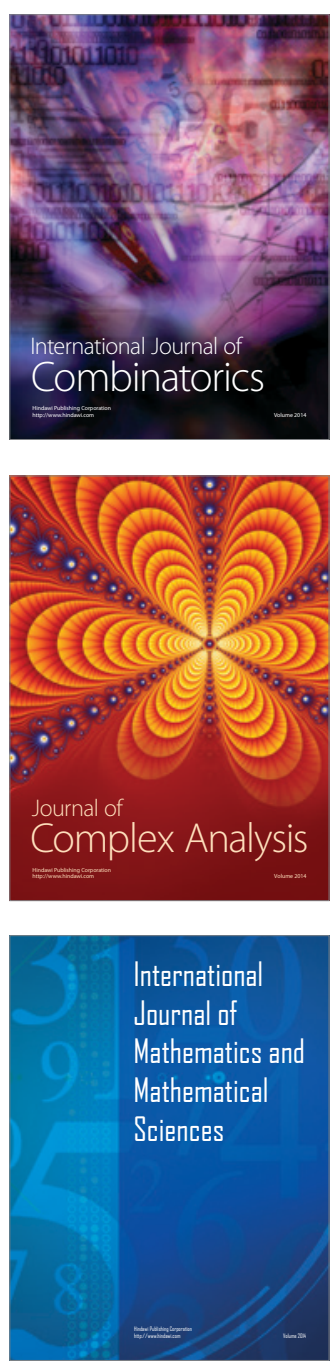
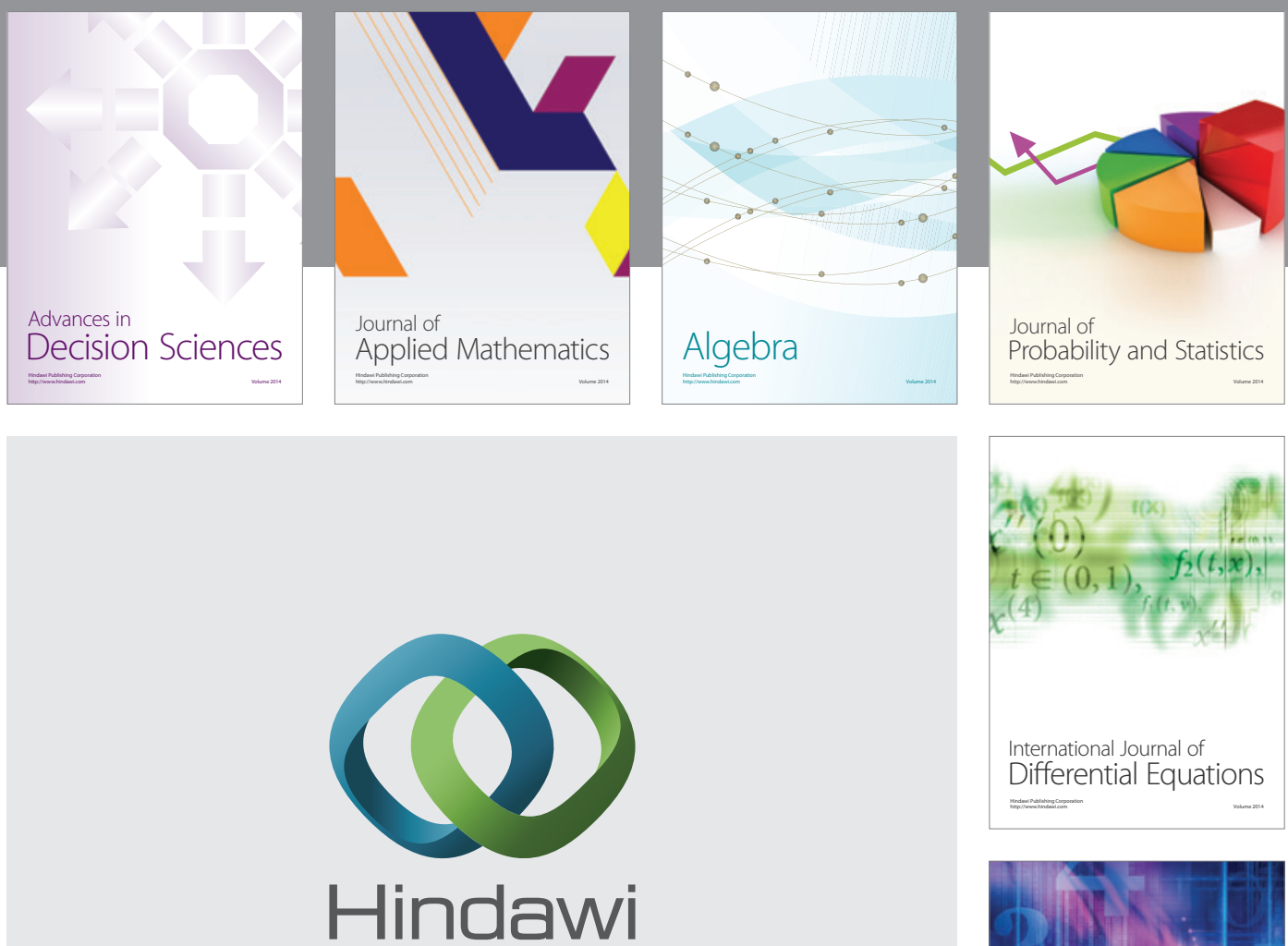

Submit your manuscripts at http://www.hindawi.com
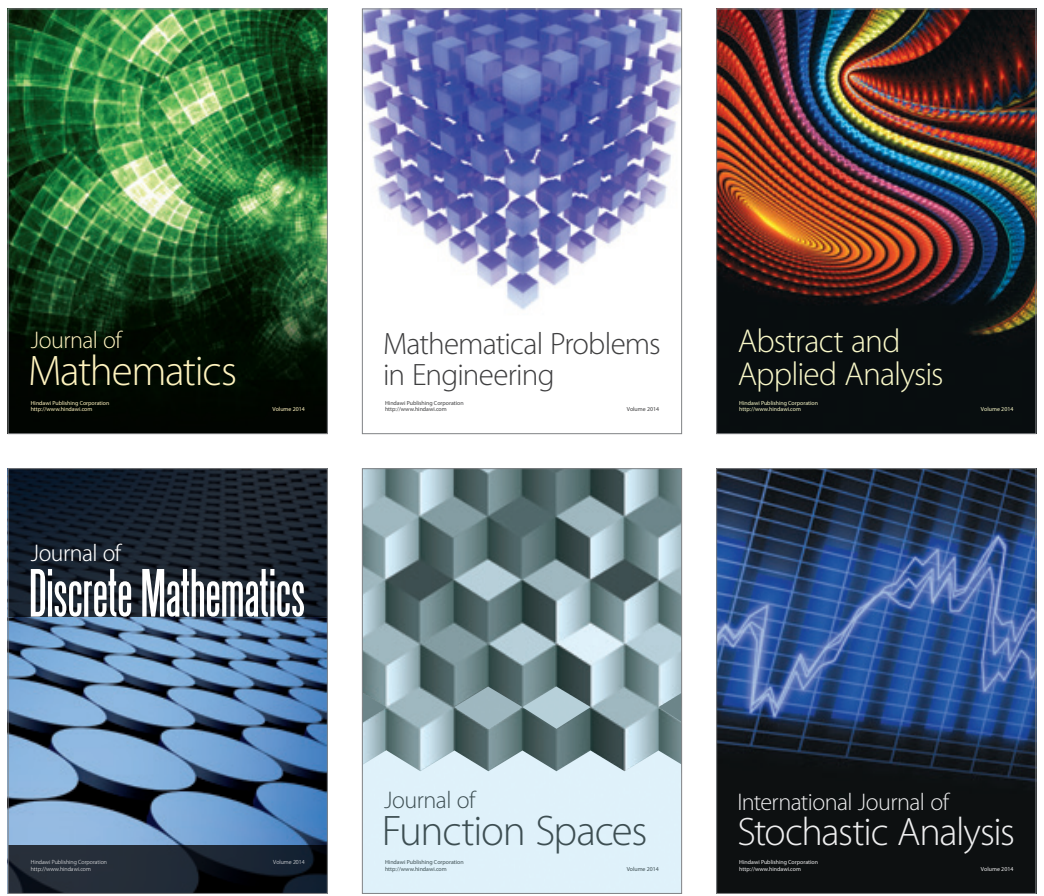

Journal of

Function Spaces

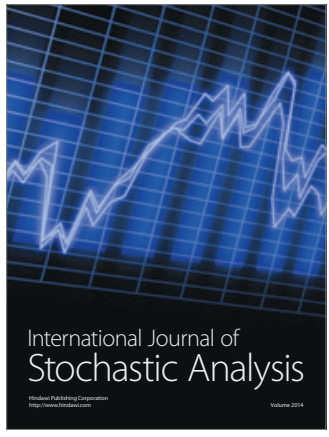

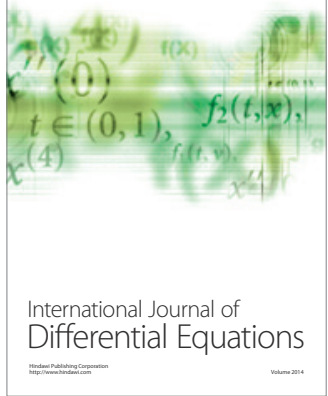
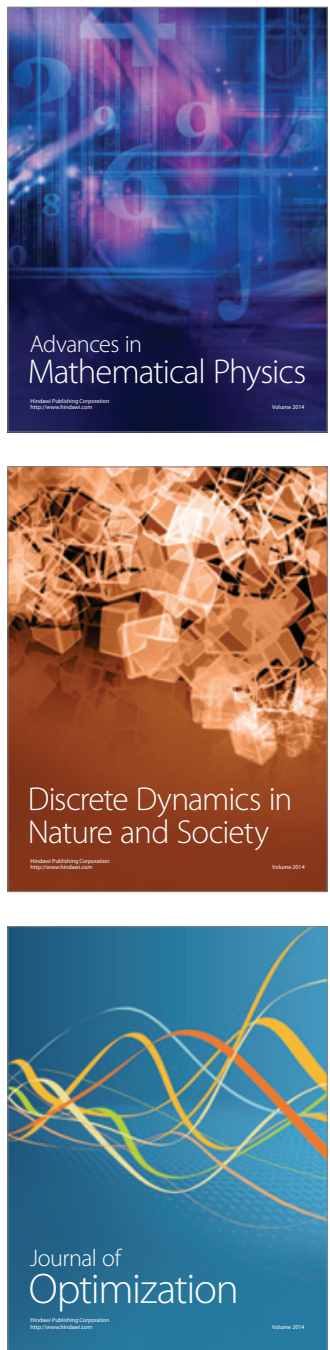